\title{
POBREZA, AMOR Y AMBICIÓN EN MARIANELA DE BENITO PÉREZ GALDÓS
}

\author{
Dr. Adel Mohamed Mohamed Nasr \\ Facultad de Lenguas y Traducción \\ Universidad de Al-Azhar
}




\title{
POBREZA, AMOR Y AMBICIÓN EN MARIANELA DE BENITO PÉREZ GALDÓS
}

\author{
Dr. Adel Mohamed Mohamed Nasr \\ Facultad de Lenguas y Traducción \\ Universidad de Al-Azhar \\ adel.nasr@azhar.edu.eg
}

\section{RESUMEN}

El propósito de este estudio consiste en esclarecer un tema tríptico-dimensional de Marianela: pobreza, amor y ambición. Este tema es recurrente y arraigado en la obra galdosiana porque se compatibiliza muy bien con las novelas de primera época que abordan todo lo social. A través de una historia idílica, Galdós quiso trazar las responsabilidades de los ricos hacia los pobres. Marianela es una tragedia amorosa, llena de pobreza y amor; ambos elementos son suficientes para despertar el entusiasmo en los personajes y tener ambición para salvarse de una mísera situación. Dicho esto, ¿qué será el resultado de la excesiva ambición? ¿Éxito o frustración?

Palabras Clave: Pérez Galdós - Marianela - pobreza - amor - ambición.

\section{ABSTRACT}

The purpose of this study is to clarify a triptych-dimensional theme in Marianela: poverty, love and ambition. This theme is recurrent and rooted in the galdosian works because it is very well compatible with the novels of the first period that address everything social. Through an idyllic story, Galdós wanted to trace the responsibilities of the rich towards the poor. Marianela is a loving tragedy, full of poverty and love; both elements are enough to awaken the enthusiasm in the characters and have ambition to save themselves from a miserable situation. That said, what will be the result of excessive ambition? Success or frustration?

Keywords: Pérez Galdós - Marianela - poverty - love - ambition. 
الملخص

\section{الققر والحب والطموح في رواية "ماريانيلا" للكاتب الإسباني "بنيتو بيريث جالدوس"}

يكمن الهدفُ من هذه الدراسةِ في تتاولِ موضوع "الفقرِ" "والحبِ" وأثرهِما على توجيه الطموحِ في رواية من روايات القرن الثاسع عَشَرَ للمؤلف الإسباني "بنيتو بيرث جالدوس"، الذي اثُتْهَر بين كثثر من النقاد بأنه من

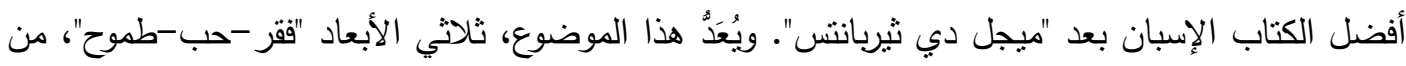

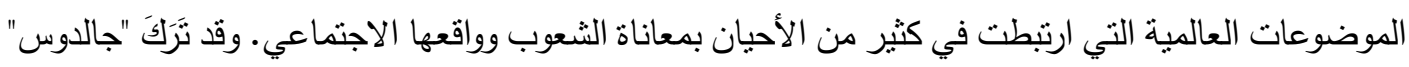

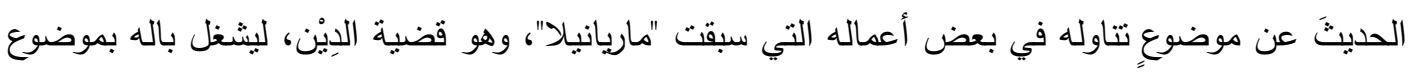
لا يقل عنه أهمية: ألا وهو مسئولية الأغنياء تجاه الفقراء، ولكنه جعل ذلك كله خلفية لقصة حب بئ بين "ماريانيلا" - تلاك الفتاة الفقبرة مادياً وجسمانيًا- وبابلو -ذللك الفتى الغني الأعمى استطاع "جالدوس" بأسلوبه الجزل وعباراته الموحية أن يوضح للقارئ أنَّ بعض أفراد المجتمع يستطيعون التغلب على الظروف الحياتية والفقر الددقع لوجود هدف سام بسعون إليه ويناضلون من أجله. ذلك هو حال

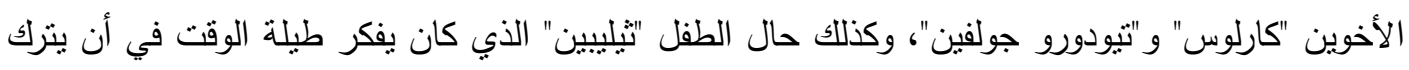
العمل في المناجم ويسافر إلى مدريد ليلتحق بإحدى المدارس هناك. كانت العلاقة بين الفقر والطموح في هذين

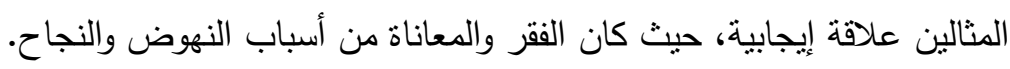
أما العلاقة ثلاثية الأبعاد: "فقر -حب-طموح"، فقد كانت من نصيب بطلة الرواية التي لم نسنطع أن تقاوم الصدمة التي تعرضت لها. عندما علمت "ماريانيلا" أن "بابلو" سيقوم بإجراء عملية يعود إليه بصره على إثرها، ويكتشف أنها ليست جميلة، انزوت عن الجميع وأخذت تفكر في الموت. ماتت الفتاة في نهاية الرواية نتيجة الفقر والجهل والحب غير المنكافئ والطموح الذي دمرته واحبطته كل الظروف المحيطة. 


\section{Introducción}

Nos parece oportuno empezar este estudio con el verso siguiente que evidencia que el ser humano ante la pobreza se queda ante dos opciones muy difíciles: vencer todo obstáculo y luchar hasta conseguir su propósito o rendirse aceptando la derrota material y psíquica, acabando su vida con un suicidio o una muerte desesperada.

Cuando me veo en lucha con el alma, le digo: adórnate con paciencia // ya que no será más que una muerte aliviadora o una gloria insuperable ${ }^{1}$.

La pobreza no debe obstaculizar la ambición o impedir lograr el avance deseado. Usando las palabras de Casalduero, en este sentido, dejamos constancia en que «no hay que tener la voluntad de morir, sino la voluntad de vivir: en lugar de regirse por dogmas o principios abstractos» (1970: 62-63). Sin embargo, en muchos casos la pobreza contradice todo desarrollo positivo y acaba con el único hilo de esperanza con el que se agarra la persona.

El objetivo de este estudio reside en evidenciar cómo la pobreza - con todos los sentidos de la palabra - ha sido vencida por el amor hasta cierto punto, la cual, al final, ha matado la ambición, en Marianela. Esta obra nos cuenta «el golpe moral sufrido por el protagonista cuando el joven a quien servía de lazarillo recobra la vista y advierte la fealdad de la muchacha, enamorándose de la otra. La delicada emoción que impregna toda la novela contrasta con la dureza de las anteriores» (García López, 1981: 566).

La motivación de este trabajo tiene doble razón: la primera es personal, la cual consiste en la admiración y el asombro producidos por la lectura de la novela, que contiene todo tipo de pasión y compasión, pobreza y concesión, odio y amor, luz y sobra, etc. La segunda razón radica en la importancia del tema tríptico-dimensional «pobreza-amor-ambición»y su aparición, a nuestro parecer, en esta obra de forma patente.

La ambición a veces mata a sangre fría. La desesperada carga sentimental y el anhelo a alcanzar un grado determinado al lado de Pablo asesinaron a Nela ${ }^{2}$, a quien dice Teodoro al final de la novela: «— Mujer, has hecho bien en dejar este mundo» ${ }^{3}$

\footnotetext{
1 'Alīi ibn Muḥammad Al-Bașrī Al- 'Alawī, citado por Abu Ŷa'far Aț-Ṭabarī, Tārīj Aț-Tabarī: Tārīj al'umam wal-mulūk (Historia Aț-Ṭabarī: historia de las naciones y los reyes), vol. 11, Beirut, Dar Suidan, 1959, p. 441.

${ }^{2}$ La protagonista de la obra se llama Marianela, pero siempre la llaman Nela.

3 Todas las citas de Marianela han sido tomadas de la siguiente edición: Benito Pérez Galdós, Marianela, edición de Francisco Caudet, Madrid, Cátedra, 5 edición, 2005. En cuanto a las citas
} 
(239). Es una pobre muchacha, fea y deforme, que sirve de lazarillo al ciego Pablo. A pesar de la diferencia social entre éste y la muchacha se enamoran; ella por amor, ambición y aspiración a sobrepasar los obstáculos y restricciones sociales, mientras que él lo hace debido a su ceguera que le impide ver la fealdad física de Nela. Esta vida trágica de Nela es el hilo principal de la novela, aunque en el trasfondo se entrelazan otros temas que evidencian la mísera situación del proletariado en aquel entonces.

Para dilucidar este tema nos parece idóneo hablar en el presente trabajo de ciertas dimensiones como el ambiente espacial y temporal; el lenguaje y su relación con la pobreza, el amor y la ambición; la pobreza, el amor, la ambición en Marianela.

\section{El ambiente espacial y temporal}

El espacio y el tiempo en que, de una parte, se publica la obra y, de otra, se desarrolla la acción gozan de envergadura artística dentro de la labor del autor. Así, el éxito de éste en presentar ambos elementos indispensables demuestra la habilidad creativa del autor y cualifica al lector para adaptarse con las acciones de la obra sin estar aterrorizado, haciéndole atraído a la hora de la lectura. Morgan Forster, a este respecto, subraya que «la sensación espacial nos anima antes que aterrorizarnos y deja tras de sí un efecto semejante a la música» (2000: 37). Por ello, la presentación que el autor hace al inicio de la obra nos hace sentir el ambiente espacio-temporal y adaptarnos psíquicamente con el mismo.

Se puso el sol. Tras el breve crepúsculo vino tranquila y oscura la noche, en cuyo negro seno murieron poco a poco los últimos rumores de la tierra soñolienta, y el viajero siguió adelante en su camino, apresurando su paso a medida que avanzaba la noche. Iba por angosta vereda, de esas que sobre el césped traza el constante pisar de hombres y brutos, y subía sin cansancio por un cerro en cuyas vertientes se alzaban pintorescos grupos de guinderos, hayas y robles (69).

El espacio geográfico o el escenario donde transcurren las acciones es el de la región de Cantabria, lugar bien conocido por el autor que lo recorrió en compañía de su amigo Pereda, ya que pasaba los veranos en su finca de Santander. Madariaga de la Campa, en este contexto, subraya que «Galdós conocía muy bien, por sus viajes con Pereda, los lugares colindantes con el ayuntamiento de Torrelavega que recorrían en sus excursiones desde Polanco» (1979: 253). Por ello, Madariaga sugiere el

sacadas de la obra objeto de estudio, nos basta solo mencionar al final de las mismas el número de página. 
municipio de Suances como localización del lugar de las minas, diciendo: «Aunque algo distante del escenario donde el novelista coloca a sus personajes existe el bufón o ufadorio de La Hilera, en Suances, que debió el novelista conocer y visitar con Pereda» (1979: 252-253). En resumidas palabras, el autor eligió el norte de España como escenario de las acciones de Marianela: «It also has the north coast of Spain for its setting; in fact Ficóbriga is visible from the mines of Socartes, where the action of Marianela transpires» ${ }^{4}$ (Pattison, 1954: 114).

Dentro de este marco general se desarrollan las acciones de Marianela, donde el lector puede apreciar tres espacios interrelacionados debido a la estrecha relación entre los personajes, que se mueven principalmente en los siguientes escenarios: paisaje rural, paisaje industrial y entornos domésticos. Como el objetivo de este estudio estriba en dilucidar la pobreza y la ambición en la obra, conviene mencionar que todo el ambiente - excepto la casa de los Penáguilas en Aldeacorba de Susorezuma de pobreza y miseria. Así, hablando de modo general de la descripción del trabajo en las minas de Socartes, el autor dice:

Hombres negros, que parecían el carbón humanado, se reunían en torno a los objetos de fuego que salían de las fraguas, y cogiéndolos con aquella prolongación incandescente de los dedos a quien llaman tenazas, los trabajaban (105).

Gustavo Correa se refiere al estado de embrutecimiento que explota las fuerzas de los obreros en las minas y deja constancia en que el pueblo de Socartes y el trabajo de las minas constituyen una fuente de animalización y esclavitud de las personas, y aun de perversión de sus sentimientos morales. Dicha atmósfera de «pesadez y servidumbre se extiende a los demás trabajadores de las minas, quienes ejecutan su trabajo como autómatas dominados por las máquinas» (Gustavo Correa, 1977: 34$35)$.

Dedicando su trabajo sobre los «Nombres y símbolos en Marianela de Benito Pérez Galdós», Fajardo (2010: 87) subraya que las minas descritas en esta obra corresponden a las minas de Mercadal, que forman parte del complejo minero de Reocín. Estas minas constituyeron una fuente de riqueza de Cartes, uno de los 102 municipios cántabros. El beneficio de las minas finaliza en 1978, es decir cien años después de la publicación de Marianela. Fajardo hace constancia, asimismo, de que Vallemojada es Torrelavega, que Teodoro Golfín bautiza con el nombre despectivo

\footnotetext{
4 "Asimismo, tiene la costa norte de España como escenario. De hecho, Ficóbriga es visible desde las minas de Socartes, donde transcurren las acciones de Marianela". Todas las traducciones que aparecen en las notas a pie de página son del investigador.
} 
de Vallefangosa. En este tenor, es preciso mencionar las palabras de Madariaga de la Campa que confirman esta tesis.

Por aquellos años la Real Compañía Asturiana explotaba desde 1856 las minas de Reocín y Mercadal, lugares entonces poco poblados y que pertenecían al ayuntamiento de Reocín, cuya descripción y ambiente reproduce el autor canario con suma exactitud. En esta área, que él indudablemente visitó cuando preparaba la novela, están Polanco, Puente San Miguel, Torrelavega, Santillana del Mar, Cartes, Reocín, Suances y Comillas (Madariaga de la Campa, 1979: 253).

Manuel Llano se refiere a las andanzas y recorridos del autor canario y los refleja en sus Artículos en la prensa montañesa, diciendo que «Huellas borradas de los zapatos polvorientos de Galdós en estos repechos, en estas tenebrosidades, en estas bárcenas recogiditas con recruces de muchos senderos que se van por allá alante. Cerca están las tierras tristes de Marianela» (1972: 718). El siguiente pasaje entre Nela y Celipín resume la situación mísera y cruel del trabajo en las minas, donde explotan, incluso, las fuerzas de los niños.

- No lo puedo remediar. Ya ves cómo nos tienen aquí. ¡Córcholis! No somos gente, sino animales. A veces se me pone en la cabeza que somos menos que las mulas, y yo me pregunto si me diferencio en algo de un borrico... Coger una cesta llena de mineral y echarla en un vagón; empujar el vagón hasta los hornos; revolver con un palo el mineral que se está lavando. ¡Ay!... (al decir esto los sollozos cortaban la voz del infeliz muchacho). ¡Cór... córcholis!, el que pase muchos años en este trabajo, al fin se ha de volver malo, y sus sesos serán de calamina... No, Celipín no sirve para esto... Les digo a mis padres que me saquen de aquí y me pongan a estudiar, y responden que son pobres y que yo tengo mucha fantesía. Nada, nada, no somos más que bestias que ganamos un jornal... ¿Pero tú no me dices nada?

La Nela no respondió... Quizás comparaba la triste condición de su compañero con la suya propia, hallando esta infinitamente más aflictiva (98).

Dicho esto, conviene referirnos, además, a que la misma Marianela y los otros habitantes de las minas son representantes del campo, de la antigüedad, de lo atrasado y de lo conectado más con la naturaleza, según el estudio llevado a cabo por Chaloupková, Krupová y Pešek (2016) sobre los «Símbolos y sueños en Marianela».

Por otra parte, Galdós describe los espacios domésticos, que, al unísono, ofrecen dos vertientes: la casa pobre de los Centeno y la casa rica de los Penáguilas. En relación con el primer espacio, es donde vive Marianela. «Está detrás de los talleres de maquinaria y junto a las cuadras» (94). La pobreza es el elemento más destacado que podemos apreciar a través de la siguiente descripción del espacio doméstico de aquella humilde casa. 
Era la morada del señor Centeno de moderna construcción, si bien nada elegante ni aun cómoda. Baja de techo, pequeña para albergar en sus tres piezas a los esposos Centeno, a los cuatro hijos de los esposos Centeno, al gato de los esposos Centeno, y, por añadidura, a la Nela, la casa [...]. Allí había sitio para todo: para los esposos Centeno, para las herramientas de sus hijos, para mil cachivaches de cuya utilidad no hay pruebas inconcusas, para el gato, para el plato en que comía el gato, para la guitarra de Tanasio, para los materiales que el mismo empleaba en componer garrotes (cestas), para media docena de colleras viejas de mulas, para la jaula del mirlo, para los dos peroles inútiles, para un altar en que la de Centeno ponía a la Divinidad ofrenda de flores de trapo y unas velas seculares, colonizadas por las moscas; para todo absolutamente, menos para la hija de la Canela (94-95).

En la conversación entre Marianela y Teodoro, observamos estas dos realidades: Nela comparte la casa con los Centeno y el ambiente está lleno de pobreza:

- ¡Pobrecita! —exclamó-. Dios no ha sido generoso contigo. ¿con quién vives?

- Con el señor Centeno, capataz de ganado en las minas.

- Me parece que tú no habrás nacido en la abundancia (88-89).

El segundo escenario es la casa de los Penáguilas. En esta casa no encontraremos aspectos de pobreza. Sin embargo, sería importante detenernos ante este espacio porque es lugar de amor y compasión, anhelo y ambición, principio y desenlace trágico de la protagonista. En esta casa nació el amor de Nela y la compasión de Pablo, hilos que forman el tejido de toda la novela.

Galdós no nos expone solamente el espacio sensorial y físico, sino también el espiritual que prevalece en toda la novela. Cuando el autor dice «... la noche, en cuyo negro seno murieron poco a poco los últimos rumores de la tierra soñolienta», nos envuelve un profundo sentimiento de tristeza y un halo de temor sobre el destino de los personajes de esta tragedia sentimental, si nos es posible llamarla así. El espacio no estaba lleno únicamente de tristeza, sino también de miedo. El narrador de la obra nos informa, a este respecto, que «el silencio que llenaba el ámbito del supuesto cráter era un silencio que daba miedo» (77). Por ello, los mismos personajes no se atreven acercarse a dichos espacios — salvo Nela y Pablo - debido al misterioso halo que motoriza sus sentimientos. Hablando con Teodoro Golfín, Pablo le confiesa: «Algunas personas tienen miedo de acercarse; pero la Nela y yo nos sentamos allí muy a menudo a oír cómo resuena la voz del abismo» (81). La mera mención de la palabra "abismo" impone unos sentimientos de temor y recelo en todo el lugar, puesto que, según la RAE, esta palabra quiere decir «Profundidad grande, imponente y peligrosa» o «Maldad, perdición, ruina moral». Así, mientras Pablo describía el ambiente espacial para el nuevo visitante de la aldea, le dice: «aquí a la 
izquierda, hay una loma. Detrás de ella se abre una boca, una sima, un abismo cuyo fin no se sabe. Se llama Trascava. Algunos creen que va a dar al mar por junto a Ficóbriga» (80). En este entorno acongojado, cuando Teodoro pregunta a Pablo por el lugar donde están y que le parece "una pesadilla", éste le responde: «Esta zona de la mina se llama la Terrible» (77).

En suma, tanto el espacio material y sensorial como el espacio espiritual están repletos de pobreza, miedo y tenebrosidad. Todos estos son factores suficientes para que los personajes anhelen a salvaguardarse, a amar y a tener ambición.

En lo que se refiere al ambiente temporal de Marianela, la obra se publicó en 1878, pero no existen en ella exactas referencias temporales que determinen el tiempo histórico porque en Marianela el autor no se preocupa por registrar acontecimientos políticos o religiosos, ya que éstos dejan de ser primordiales, sino que estaba obsesionado por reflejar los problemas sociales y culturales de la época. Sin embargo, podemos pensar que, como esta obra pertenece a las novelas clasificadas por el autor mismo como «novelas de la primera época», que tratan los conflictos actuales de los años setenta, el espacio temporal de Marianela puede fecharse alrededor del tercer cuarto del siglo XIX. En este tenor, Pattison destaca el problema social que encierra Marianela:

In Marianela Galdós turns away from the religious problem to tell an idyllic story of tragic love and to study the responsibilities of the rich towards the poor ${ }^{5}$ (Pattison, 1954: 114).

En cuanto al tiempo interno de Marianela, las acciones transcurrieron aproximadamente en un mes. O sea, la llegada de Teodoro Golfín ocurre en el mes de septiembre: «...le he conocido a usted y seremos amigos, quizás muy amigos... Vaya, adiós; a casa pronto, que el fresco de septiembre no es bueno» (85) y termina con la muerte de Nela en el 12 de octubre, ya que en la lápida figura esta fecha «María Manuela Téllez, Reclamóla el cielo, En 12 de octubre de 186... » (241).

Además, podemos apreciar otro espacio temporal que consiste en el flashback que hace Nela para contar algunos recuerdos acerca de su vida y la de sus padres. Este espacio podemos denominarlo el espacio psicológico que gira solo en la mente de Nela y abarca 16 años, la edad de ésta. Nadie se da cuenta de ese tiempo y, por ello, Nela, cuando narra dichos recuerdos, los presenta de forma impersonal:

\footnotetext{
5 "En Marianela, Galdós se aleja del problema religioso para contar una historia idílica de una tragedia amorosa y abordar las responsabilidades de los ricos hacia los pobres".
} 
"Dicen". Además de todo esto, es un tiempo lleno de pobreza y ambición frustrada de los padres de Nela.

-Dicen que mi madre vendía pimientos en el mercado de Villamojada. Era soltera. Me tuvo un día de Difuntos, y después se fue a criar a Madrid. [...] Yo estaba ya criada por una hermana de mi madre, que era también soltera, según dicen. [...] Dicen que mi madre me recogió después de la caída. Mi padre cayó enfermo, y como mi madre no le quiso asistir, porque era malo, él fue al hospital donde dicen que se murió. Entonces vino mi madre a trabajar a las minas. Dicen que un día la despidió el jefe porque había bebido mucho aguardiente... [...] -Se fue a un agujero muy grande que hay allá arriba (89-90).

A lo largo de este tiempo - sea el mes en que transcurren las acciones o los dieciséis años del flashback - podemos observar nítidamente el volumen de los sufrimientos que enfrentan a los personajes de la novela, como lo hemos indicado, como los Centeno, Marianela y su familia, los obreros en la mina, etc.

A pesar de la desolación, la devastación, la pobreza, la miseria y el sentimiento de soledad, encontrados en el ambiente espacial y temporal de Marianela, el autor no se olvidó de darnos un rayo de esperanza. No puede ser todo de ruina y desesperación. Así, la negrura de la noche se convierte en el brillo del sol que calienta sin quemar y el espacio desolado y pobre se trasforma en un campo florido, etc. Galdós, en este contexto, declara que Nela y Pablo: «subieron una cuesta por entre frondosos castaños y nogales» (115). En otra ocasión, el autor, hablando de los recuerdos de Nela, afirma:

La hermosura del país, con cuyos accidentes se sentía unida por una especie de parentesco, la escasa felicidad que había gustado en él, la miseria misma, el recuerdo de su amito y de las gratas horas de paseo por el bosque y hacia la fuente de Saldeoro, los sentimientos de admiración o de simpatía, de amor o de gratitud que habían florecido en su alma en presencia de aquellas mismas flores, de aquellas mismas nubes, de aquellos árboles frondosos, de aquellas peñas rojas, y como asociados a la belleza, al desarrollo, a la marcha y a la constancia de aquellas mismas partes de la Naturaleza (201).

En suma, Galdós, como autor realista, especificó para el escenario de las acciones de Marianela un espacio - lugar y tiempo - real y objetivo. Las características de dicho espacio aparecen bien definidas y dibujadas debido a su similar realista en el norte de España. Es más, se entretejen en este escenario los acontecimientos de una tragedia amorosa, cuyo trasfondo espacial está lleno de pobreza, amor y ambición. 


\section{El lenguaje y su relación con la pobreza, el amor y la ambición}

El lenguaje empleado en una obra literaria no puede ser separado de la ideología, el pensamiento, los sentimientos de los personajes, etc. Conviene referirnos aquí a la invitación de Yahya Ḥaqqī para que los escritores siguieran un nuevo método de escritura, esto es «un estilo científico caracterizado por la exactitud, precisión y claridad, ya que el vocablo para mí es el recipiente del pensamiento» (1992: 44). Esto quiere decir que la lengua utilizada debe concordar siempre con el personaje que lo reproduce, su posición social, profesión, educación, aficiones, ambiciones, forma de vivir y pensar, etc. Por ello, cuando Ricardo Gullón aborda el análisis del personaje, se interesa por la dimensión psicolingüística de éste: «este tipo de análisis se atenderá a las palabras, pero no tratándolas como materia inerte, sino como signos que para ser descifrados imponen el estudio de su contexto en frase y situación» (1980: 37). El mismo Galdós, a este respecto, confirma que el arte de componer la novela estriba en la reproducción de muchas dimensiones, incluyendo en éstas «el lenguaje que es la marca de la raza» (1999: 220).

Dicho esto, en Marianela podemos observar la existencia de diferentes niveles del lenguaje según el personaje que lo reproduce. Es decir, el autor emplea en Marianela diversos niveles de lenguaje como el retórico en los discursos de Teodoro Golfín, el sencillo y coloquial de Celepín, el científico y técnico en las descripciones de las minas y la ceguera de Pablo y el lenguaje amoroso y las declaraciones apasionadas de Pablo.

Por lo que respecta a la relación del lenguaje con los aspectos referidos en el título, Galdós pudo con singular maestría correlacionar el lenguaje con la pobreza, el amor y la ambición. En primer lugar, los vocablos "pobreza" y sus derivaciones fueron mencionados con abundancia en Marianela para enfatizar la existencia del problema y el sufrimiento de amplia gama de personas del mismo. Conviene, en este contexto, decir que la pobreza, en general, se refiere a la escasez de algo. En Marianela, observamos que hay varios tipos de esta escasez cuyos efectos han sido graves. Así el lector puede hallar pobreza material, pobreza de subsistencia, pobreza física, pobreza intelectual, pobreza espiritual, etc. Celepín se queja de la situación mísera de su familia y su deseo de ir a estudiar en Madrid: «Les digo a mis padres que me saquen de aquí y me pongan a estudiar, y responden que son pobres»; el narrador habla del origen de los hermanos Golfín y su procedencia pobre, utilizando las palabras "humilde", "luchar", "ignorancia", "pobreza", "sucumbir" y "miseria" para denotar el volumen de este aspecto en la sociedad: «Nacidos en la clase más humilde, habían luchado solos en edad temprana por salir de la ignorancia y de la pobreza, viéndose a punto de sucumbir diferentes veces; $[\ldots]$ al fin, llegaron 
jadeantes a la ansiada orilla, dejando atrás las turbias olas en que se agita en constante estado de naufragio el grosero vulgo» (136); Sofía, hablando con Teodoro, está convencida de la existencia de un "desamparo" en que vive mucha gente y de que la sociedad, además, no puede intervenir: «-¡Desamparado de la sociedad! Hay algunos que lo están... -dijo Sofía con impertinencia-. La sociedad no puede amparar a todos. Mira la estadística, Teodoro; mírala y verás la cifra de pobres... Pero si la sociedad desampara a alguien...» (143-144); Teodoro esclarece con términos muy parecidos su trayectoria vital y convoca a todos los niños perdidos del mundo: «Óiganme todos los pobres, todos los desamparados, todos los niños perdidos... Yo entré en los Escolapios como Dios quiso; yo aprendí como Dios quiso... Un bendito padre diome buenos consejos y me ayudó con sus limosnas...» (148). Además de lo mencionado, el autor se sirvió de abundantes palabras cuyo único fin en la obra es demostrar que la pobreza abrumaba la sociedad en aquel tiempo.

En segundo lugar, el amor constituye la segunda vertiente cuyo tratamiento requiere el uso de un lenguaje lleno de pasión y amor. Influenciado por su experiencia amorosa con Sisita, Galdós tenía listo el vocabulario amoroso y las expresiones emocionables, puestos todos en funcionamiento para expresar varios sentimientos contradictorios de los personajes, Pablo y Nela. Debido a la importancia de esta dimensión en la obra, Gonzalo de Sobejano dedicó un artículo sobre «Galdós y el vocabulario de los amantes», poniendo énfasis en que Marianela se cuenta de entre las novelas «muy ilustrativas a este propósito» (1966: 86).

Así, el capítulo VI se titula "Tonterías" y éstas brotan del entusiasmo amoroso; «el amor, si está verdaderamente vivo, es euforia, y no puede menos de manifestarse con frondosa locuacidad; empujadas por la savia desbordante del amor, las palabras redundan, expresando el doble deseo de los amantes: unión de los dos, separación de los demás» (Sobejano, 1966: 87). Galdós presenta a los enamorados disfrutando de la naturaleza en una amistosa compañía y utilizando vocablos de amor y contento:

¡Ay, qué hermoso día y qué contenta estoy! (113).

Cuando Pablo pregunta a Nela acerca de su sentimiento cuando están solos los dos, ésta le responde:

- Pues siento que me nace dentro del pecho una frescura, una suavidad dulce... (113).

En otra ocasión, Pablo habla de su anhelo de tener ojos para contemplar la belleza de Nela, diciendo: 
Para que los dos seamos uno solo, me falta muy poco; sólo me falta verte y recrearme en tu belleza, con ese placer de la vista que no puedo comprender aún, pero que concibo de una manera vaga. Tengo la curiosidad del espíritu, pero la de los ojos me falta. Supóngola como una nueva manera del amor que te tengo. Yo estoy lleno de tu belleza; pero hay algo en ella que no me pertenece todavía. [...] Tu extraordinaria bondad, tus nobles prendas, tu seductora belleza, que ha de cautivar los corazones y encender el más puro amor en cuantos te traten, asegurando un porvenir risueño. Yo te juro que te querré mientras viva, ciego o con vista, y que estoy dispuesto a jurarte delante de Dios un amor grande, insaciable, eterno (133).

Por último, Pablo enumera las cualidades de su amada, que le cautivaron el corazón y le hicieron alegre, a pesar de la triste atmósfera en que vivía debido a su ceguera:

-Sí, tú eres la belleza más acabada que puede imaginarse -añadió Pablo con calor-. ¿Cómo podría suceder que tu bondad, tu inocencia, tu candor, tu gracia, tu imaginación, tu alma celestial y cariñosa que ha sido capaz de alegrar mis tristes días; cómo podría suceder, cómo, que no estuviese representada en la misma hermosura?... Nela, Nela -añadió balbuciente y con afán-. ¿No es verdad que eres muy bonita? (123).

Es de mencionar, en este tenor, que el lenguaje amoroso de Nela «no deja de ser en ningún momento el verosímil en una muchacha ignorante y enloquecida por la alegría de su cariño» (Sobejano, 1966: 87). Por ello, cuando Nela habla idílicamente con Pablo, se vale de un lenguaje sencillo y coloquial, lleno de exclamaciones y vocativos para manifestar su ternura y amor que siente hacia el joven:

- Si está esto lleno de flores... -dijo la Nela-. ¡Madre!, ¡qué guapas! (115).

-Madre Divinísima, iqué poca ciencia! (116).

¡Cómo se conoce que no lo ves! ¡Madre del Señor! (116-117).

¡Ay! ¡Cuánto te quiero, niño de mi alma! (170).

... niño de mi corazón (112).

Queda por demostrar el uso del lenguaje relacionado con el tercer ángulo del triángulo, que hemos venido describiendo: pobreza, amor y ambición. En varias ocasiones, el autor se vale de vocablos explícitos como "ambición", "anhelo", "deseo" "aspiración", "voluntad", para indicar la intimidad de los personajes y su actitud ante la mísera y severa situación social que viven. Así, habla del crimen de "matar la ambición" de millones de seres y "encerrarles en determinados círculos": 
... hay una plaga más terrible, y es el positivismo de las aldeas, que petrifica millones de seres, matando en ellos toda ambición noble y encerrándoles en el círculo de una existencia mecánica, brutal y tenebrosa (99).

En otra ocasión, se refiere a la "falta de carácter y de ambición" de Tanasio debido a la forma de vida con la cual se familiarizó. La muerte de la ambición y la aniquilación de su voluntad retornan a su infancia cuando le trataban como una máquina:

Su falta de carácter y de ambición rayaban en el idiotismo. Encerrado en las cuadras desde su infancia, ignorante de toda travesura, de toda contrariedad, de todo placer, de toda pena, aquel joven, que ya había nacido dispuesto a ser máquina, se convirtió poco a poco en la herramienta más grosera. El día en que semejante ser tuviera una idea propia, se cambiaría el orden admirable de todas las cosas, por el cual ninguna piedra puede pensar (101).

Como estos personajes no se rebelaban o no se quejaban de la degradante miseria en que vivían, ni mostraban afán de emancipación ni anhelo de otra vida mejor, nadie más se movería para cambiar esta realidad.

En cuanto a Teodoro y su hermano Carlos, su salvación era la educación. Es más, opinaban que la voluntad de luchar contra las malas circunstancias constituye la piedra angular en lograr el triunfo. Así, observamos que el autor, cuando habla de estos personajes, se vale de vocablos como: "progreso", "voluntad", "ambición", "triunfo", "fuerza", "anhelar" "corazón aventurero", etc.

- ... Este es el resultado de nuestra educación, [...] Como no hemos sido criados con mimos; como desde nuestra más tierna infancia nos acostumbramos a la idea de que no había nadie inferior a nosotros... Los hombres que se forman solos, como nosotros nos formamos; los que, sin ayuda de nadie, ni más amparo que su voluntad y noble ambición, han logrado salir triunfantes en la lucha por la existencia... (147).

Ayudó a éste con todas sus fuerzas mientras el joven lo necesitara, y cuando le vio en camino, tomó el que anhelaba su corazón aventurero, yéndose a América (136).

En suma, Galdós pudo marcar los personajes, su pertenencia o afiliación, su condición social, sus sentimientos, aspiraciones, etc. a través del lenguaje empleado en Marianela. Esta creatividad expresiva estampa todas las dimensiones de la obra $\mathrm{y}$, en particular, los sentimientos de amor y ambición que desbordan los corazones de los personajes. 


\section{Pobreza, amor y ambición en Marianela}

El tema tríptico-dimensional, «pobreza, amor y ambición», tendría que ser el fruto de la pluma de un novelista comprometido que registra todos los dolores de sus personajes causados por la desigualdad social, un hombre apasionado e impregnado de una experiencia amorosa, y, por último, un autor ambicioso que no escatima esfuerzo en buscar soluciones para salvar a éstos de la ruina, aunque la ambición del autor no impide el destino trágico del personaje. Pérez Galdós, en este sentido, se comparaba con Charles Dickens, Emilio Zola y Balzac ${ }^{6}$ debido al interés prestado al primer aspecto, esto es su compromiso:

La aplicación de estos principios, unida a un afán de lucro desmedido que se dio a entre los empresarios, llevó a la sociedad europea a una situación de explotación inhumana de la clase obrera. [...] El perfil de esta sociedad inhumana ha quedado retratado en las obras de Charles Dickens, Emilio Zola y Benito Pérez Galdós (Esther Jimeno, et. al, 1983: 102).

De igual modo, sus fecundos sentimientos idílicos y diversas relaciones amorosas influyeron en su obra literaria y le hicieron dominar el lenguaje amoroso y expresarlo muy bien ${ }^{7}$. Pérez Galdós, en este tenor, fue un «hombre cuyas pasiones amorosas debieron de ser vivas y profundas, muy propenso al enamoramiento y muy

\footnotetext{
${ }^{6}$ Para más información sobre este tema, véase: Charles David Ley, «Galdós comparado con Balzac y Dickens, como novelista nacional», en Actas del primer congreso internacional de estudios Galdosianos, 1977, pp. 291-295; Lisa Pasto-Crosby, «Dickens y Galdós: la perspectiva múltiple», en IV Congreso galdosiano, pp. 177-188; Lieve Behiels, «Anagnórisis en Galdós y Dickens», en Actas del noveno congreso internacional de estudios galdosianos, Cabildo Insular de Gran Canaria, 2009, pp. 440-448; Matilde L. Boo, «Galdós y Zola, dos teóricos del teatro», en Actas del segundo congreso internacional de estudios Galdosianos II, Volumen 2, Cabildo Insular de Gran Canaria, 1980, pp. 135-149. Darío Villanueva, «Tres teorías, tres realismos: Zola, Galdós, James», en 1616: Anuario de Literatura Comparada, 1, 2011, 267-291.

${ }^{7}$ Varios autores han abordado este tema, destacando las diversas relaciones amorosas del autor. Así, por ejemplo, véase: Walter T. Pattison, «Tow Women in the life of Galdós», en Anales galdosianos, The University of Texas, Austin, Año VIII, 1973, pp. 23-31; A. F. Lambert, «Galdós and Concha Ruth Morell», en Anales galdosianos, The University of Texas, Austin, Año VIII, 1973, pp. 33-49; Carmen Bravo-Villasante, «Aspectos inéditos de Emilia Pardo Bazán (Epistolarios con Galdós)», en Actas del séptimo congreso de la asociación internacional de hispanistas, 1971, pp. 199-204; Corina Alonso García, «Galdós y sus relaciones femeninas: María D. M.», en Actas del tercer congreso internacional de estudios galdosianos, tomo I, Cabildo Insular de Gran Canaria, Las Palmas de Gran Canaria, 1989, pp. 11-22; Arsenio Escolar, «Las mujeres de Galdós», 21 febrero de 2010, disponible en: https://blogs.20minutos.es/arsenioescolar/2010/02/21/las-mujeres-galdais/ (último acceso: 28/11/2018); Félix Casanova, «Cartas de amor clandestino entre Galdós y Pardo Bazán formato digital», en Historias de nuestra historia, 2 de noviembre de 2016, en https://hdnh.es/cartas-de-amorclandestino-entre-galdos-y-pardo-bazan-en-formato-digital/ (último acceso en: 28/11/2018). Madariaga de la Campa, «Los amores de Galdós» en Pérez Galdós: bibliografía santanderina, Santander, Institución cultural de Cantabria, 1979, $1^{\text {a }}$ edición.
} 
reservado también en los comentarios de sus aventuras y conquistas femeninas» (Madariaga de la Campa, 1979: 71). Sin penetrarnos en la cuestión de que Galdós era "mujeriego" o "amante de las mujeres", es indispensable decir que el autor canario «tenía una vida de enamoramiento sin límites» (Julieta Sanguino, 2016) y que «le gustan las mujeres... lo que nadie puede imaginarse, pero todo se lo calla y de estas cosas ni Dios le saca una palabra» (Zulueta, 1968: 324).

El compromiso y el amor que impregnaban la mente y el corazón de Galdós han de ser capaces de empaparle de ambición y motivación para encontrar soluciones para las personas de su comunidad, las cuales vienen encarnadas por los personajes de su obra literaria.

En suma, todos estos aspectos que formaban parte de la vida personal del propio autor han tenido ecos en Marianela, cuya polidimensionalidad ha sido patente y enriquecedora, como siempre, de la obra galdosiana.

Dicho esto, conviene dejar constancia en que la pobreza - primer elemento de este tema tríptico-dimensional - constituye el factor esencial por el cual los personajes anhelan zafarse de su condición social y encontrar una vida mejor. Así, a lo largo de la novela encontramos pobreza, como lo hemos indicado en el ambiente espacial y temporal. La pobreza está en todas partes: pobreza física es la fealdad de Nela, pobreza de sentimientos es el egoísmo de Pablo, pobreza de recursos materiales para sobrevivir es la de los obreros de la mina, la familia de los Centeno y los hermanos Golfín, etc.

Marianela es una muchacha pobre cuyo origen mísero deja profundo sentimiento de tristeza y aislamiento melancólico. En su primer encuentro con Teodoro Golfín, Nela le narra su historia de la manera siguiente:

-Dicen que mi madre vendía pimientos en el mercado de Villamojada. Era soltera. Me tuvo un día de Difuntos, y después se fue a criar a Madrid. [...] Mi padre era el encargado de encenderlos y limpiarlos (faroles en las calles). Yo estaba ya criada por una hermana de mi madre, que era también soltera, según dicen. Mi padre había reñido con ella... Dicen que vivían juntos... todos vivían juntos... y cuando iba a farolear me llevaba en el cesto, junto con los tubos de vidrio, las mechas, la aceitera... Un día dicen que subió a limpiar el farol que hay en el puente; puso el cesto sobre el antepecho, yo me salí fuera y caíme al río. [...]

\footnotetext{
${ }^{8}$ A este respecto, Gregorio Marañón, que fue médico, amigo y confidente de Galdós afirma: «... Galdós, igualmente soltero, por probable influencia de la emoción materna, hombre superviril y mujeriego, aunque tímido con las mujeres y de inagotable ternura para los niños» (Marañón, 1962: 219).

${ }^{9}$ Véase Julieta Sanguino, «Incesto y poliamor en la vida de Galdós», en CC/ Historia, en el 17 de noviembre 2016, en https://culturacolectiva.com/historia/incestos-y-poliamor-en-la-vida-de-galdos
} 
- Dicen que mi madre me recogió después de la caída. Mi padre cayó enfermo, y como mi madre no le quiso asistir, porque era malo, él fue al hospital donde dicen que se murió. Entonces vino mi madre a trabajar a las minas. Dicen que un día la despidió el jefe porque había bebido mucho aguardiente...

- Y tu madre se fue... Vamos, ya me interesa esa señora. Se fue...

- Se fue a un agujero muy grande que hay allá arriba -dijo Nela, deteniéndose ante el doctor y dando a su voz el tono más patético- y se metió dentro.

- ¡Canario! ¡Vaya un fin lamentable! Supongo que no habrá vuelto a salir.

- No, señor -replicó la Nela con naturalidad-. Allí dentro está.

- Después de esa catástrofe, pobre criatura -dijo Golfín con cariño-, has quedado trabajando aquí. Es un trabajo muy penoso el de la minería (89).

La pobreza física de Nela es también muy evidente y es la causa por la cual Pablo dejó de unirse con ella. El autor la describe muy brevemente diciendo: «Nela, criatura abandonada, sola, inútil, incapaz de ganar jornal, sin pasado, sin porvenir, sin abolengo, sin esperanza, sin personalidad, sin derecho a nada más que al sustento» (102). En su conversación con Nela, Teodoro Golfín añade a estas descripciones: «Tú estás teñida del color del mineral; estás raquítica y mal alimentada» (90), lo que indica que el único derecho que ella tiene —el sustentono lo consigue de forma suficiente y honrada. La misma Nela reconoce su fealdad y no escatima esfuerzos en rebelarse contra su situación, llamando a la Virgen María con el deseo de que ésta la salve de la perplejidad en que se vio metida:

Encerrándose en sus conchas, Marianela habló así:

- Madre de Dios y mía, ¿por qué no me hiciste hermosa? ¿Por qué cuando mi madre me tuvo no me miraste desde arriba?... Mientras más me miro más fea me encuentro. ¿Para qué estoy yo en el mundo?, ¿para qué sirvo?, ¿a quién puedo interesar?, a uno solo, Señora y madre mía, a uno solo que me quiere porque no me ve. ¿Qué será de mí cuando me vea y deje de quererme?... porque ¿cómo es posible que me quiera viendo este cuerpo chico, esta figurilla de pájaro, esta tez pecosa, esta boca sin gracia, esta nariz picuda, este pelo descolorido, esta persona mía que no sirve sino para que todo el mundo le dé con el pie. ¿Quién es la Nela? Nadie. La Nela sólo es algo para el ciego. Si sus ojos nacen ahora y los vuelve a mí y me ve, caigo muerta. [...] Sí, sí; que se trague la tierra mi fealdad. Yo no debía haber nacido (169).

La pobreza y la miseria colmaron a Nela hasta el punto de que Montesinos dijo, a este respecto, que Nela es «criatura de aquel Galdós que tan hondamente simpatizó con esos patéticos seres nacidos para sufrir, irremediablemente, pues no se descubre medio alguno de redimirlos» (1968: 239).

El egoísmo de Pablo cuando recupera la vista es pobreza de sentimientos y falta de apoyo moral a la pobrecita. Nela tenía un presentimiento de la mala suerte que le iba a tocar. Por ello, leemos el siguiente monólogo que revela la actitud de 
Nela frente esta cuestión: «¿Siento yo que recobre la vista? No, eso no, eso no. Yo quiero que vea. Daré mis ojos porque él vea con los suyos; daré mi vida toda» (169). A pesar de este sacrificio que ella está dispuesta a llevar a cabo, Pablo se olvida de las promesas sentimentales a su lázaro; el amor se convierte en mera compasión; el anhelo se transforma en desdén; la esperanza se transmuta en miedo; etc.

La familia de los Centeno, que daba asilo a la niña, también nadaba en la pobreza. Quizás por eso el autor titula el capítulo IV "la familia de piedra". Es una familia formada por los padres y cuatro hijos. Los padres, Sinforoso y Señana, representaban la ignorancia y la avaricia y, por eso, hacían trabajar mucho a los niños para ahorrar dinero. Celipín, que era el más pequeño de la familia y frisaba en los doce años, hablaba de la forma siguiente sobre la mísera situación de su familia, mostrando su odio hacia la misma:

- Que no quiero a mi madre ni a mi padre como los debiera querer.

[...]

- No lo puedo remediar. Ya ves cómo nos tienen aquí. ¡Córcholis! No somos gente, sino animales. A veces se me pone en la cabeza que somos menos que las mulas, y yo me pregunto si me diferencio en algo de un borrico... Coger una cesta llena de mineral y echarla en un vagón; empujar el vagón hasta los hornos; revolver con un palo el mineral que se está lavando. ¡Ay!... (al decir esto los sollozos cortaban la voz del infeliz muchacho). ¡Cór... córcholis!, el que pase muchos años en este trabajo, al fin se ha de volver malo, y sus sesos serán de calamina... No, Celipín no sirve para esto... (98).

La pobreza intelectual, asimismo, no deja de formar parte de este entramado dentro de la familia Centeno, puesto que tocante a las facultades intelectuales, la cabeza de Sinforoso «en opinión de muchos, rivalizaba en dureza con el martillopilón montado en los talleres» (100). La cuestión es muy diferente en cuanto a su esposa, Señana, «que parecía mujer de muchísimo caletre y trastienda, y gobernaba toda la casa como gobernaría el más sabio príncipe sus Estados» (100).

El amor, a renglón seguido, representa una veta temática muy importante en Marianela, obra en la cual se desarrolla una amistad apasionada entre Pablo y Nela hasta el punto en que Pablo promete casarse con ésta. Nela se encuentra perdidamente enamorada de Pablo. Pero, como lo indicamos en su lugar, es un amor frustrado debido a un entramado de factores: pobreza física de Nela, egoísmo de Pablo, apariencia social de la familia Penáguilas, etc. Es de particular importancia aquí referirnos a que el autor refleja con esta relación amorosa una parte de sus recorridos personales. Ricardo Gullón, en este sentido subraya que la composición de Marianela representa: 
Un interludio sentimental. Un retorno a los sentimientos de juventud, al amor llamado a perderse por ser puro e irreal y adolescente. Marianela, Nela, no solo es la muchacha fea amada por el ciego y desconocida por el vidente, sino llama de pureza que el viento del recuerdo extrajo de algún rescoldo, de alguna brasa no apagada en el corazón del novelista (Gullón, 1973: p. 73).

Aunque Galdós tuvo varias relaciones amorosas - como su relación con Dolores Macías Sánchez, María Josefa Washington de Galdós, conocida por Sisita, Juanita Lund, Emilia Pardo Bazán, Concha-Ruth Morell, Lorenza Cobián y Teodosia Gandarias - la historia de esta novela se identifica con su relación con Sisita, su amor frustrado. Ricardo Gullón, a este respecto, subraya:

En Nela hay mucho de Sisita, la amada juvenil de Galdós, y esa remembranza lejana, hermoseada por la distancia y la adscripción al pasado irreversible, proyecta sobre la narración una fragancia. Pues ésta es la novela romántica de Galdós, la compensación por el amor frustrado; el imposible amor, la suprema pureza se incorporaron al orbe ficticio gracias a esta figura ideal. Es emocionante recordar que cuando Nela, la más amada de sus figuras, convertida en personaje de comedia — en la escenificación realizada por Serafín y Joaquín Álvarez Quintero-, apareció en el teatro madrileño con la presencia y voz de Margarita Xirgu, el viejo novelista, ya ciego, al oír que la actriz empezaba a hablar con las palabras puestas por él en boca de aquélla, se levantó tembloroso y vacilante, patéticamente vacilante, estremeciéndose como un sarmiento retrocido por el fuego, tendió los brazos al escenario y, mirando con ojos muertos al lugar de donde la voz salía, mientras las lágrimas corrían por sus mejillas, musitó, sollozando «iNela! ¡Nela!» (Gullón, 1973: 73).

Dibujada ya dicha atmósfera de pesadez y servidumbre que se extiende a la mayor parte de los personajes y el amor de los héroes nos resulta adecuado referirnos a la tercera dimensión constituyente de este estudio. La ambición, como consecuencia natural de la insatisfacción de una situación social determinada, ha sido presentada de diferentes matices. Así, los hermanos Golfín, en primer lugar, crecieron en el seno de una familia humilde y, como tenían ambición a vencer las circunstancias, decidieron luchar contra todo para salvaguardase. Por ello, Casalduero llama a Teodoro «el nuevo conquistador, el nuevo héroe» (1970: 62) porque, aunque era de baja extracción social, luchó por la vida, formándose a sí mismo, y triunfó. Galdós dilucida la pobreza en que nacieron, el amor que profesaban y la ambición que tenían de la forma siguiente:

Los dos hermanos se profesaban el más vivo cariño. Nacidos en la clase más humilde, habían luchado solos en edad temprana por salir de la ignorancia y de la pobreza, viéndose a punto de sucumbir diferentes veces; mas tanto pudo en ellos el impulso de una voluntad heroica, que al fin llegaron jadeantes a la ansiada orilla, dejando atrás las turbias olas en que se agita en constante estado de naufragio el grosero vulgo. 
Teodoro, que era el mayor, fue médico antes que Carlos ingeniero. Ayudó a éste con todas sus fuerzas mientras el joven lo necesitara, y cuando le vio en camino, tomó el que anhelaba su corazón aventurero, yéndose a América. Allá trabajó juntamente con otros afamados médicos europeos, adquiriendo bien pronto fama y dinero. Hizo un viaje a España, tornó al Nuevo Mundo, vino más tarde para regresar al poco tiempo. En cada una de estas excursiones daba la vuelta a Europa para apropiarse los progresos de la ciencia oftálmica que cultivaba (136).

Como queda claro, este modelo de ambición es positivo y la persona triunfó porque tenía la voluntad de lograrlo.

En este orden de cosas, tenemos otro modelo de ambición y voluntad positivas, pero no llegamos a saber cómo fue el resultado. Los padres de Celepín no quieren sacarle del trabajo en las minas. Pero, el niño tiene muchas aspiraciones y anhela salvaguardarse de esta pesada y severa atmósfera. Las minas para el niño se parecen a una cárcel que encadena su libertad. Por ello, busca otros rumbos para dejar este ambiente y recibir la enseñanza en Madrid. Él, en repetidas ocasiones, afirma "Yo no sirvo para esto" refiriéndose al trabajo en las minas:

El domingo, si me dejan ir a Villamojada, he de comprar una cartilla para aprender a leer, ya que aquí no quieren enseñarme. ¡Córcholis! Aprenderé solo. ¡Ay!, Nela, dicen que D. Carlos era hijo de uno que barría las calles en Madrid. Él solo, solito él, con la ayuda de Dios, aprendió todo lo que sabe.

- Puede que pienses tú hacer lo mismo, bobo.

- ¡Córcholis! Puesto que mis padres no quieren sacarme de estas condenadas minas, yo me buscaré otro camino; sí, ya verás quién es Celipín. Yo no sirvo para esto, Nela. Deja tú que tenga reunida una buena cantidad, y verás, verás, cómo me planto en la villa y allí o tomo el tren para irme a Madrid, o un vapor que me lleve a las islas de allá lejos, o me meto a servir con tal que me dejen estudiar. [...]

- ¿Pero tú me tienes por bobo?... ¡Ay! Nelilla, estoy rabiando. Yo no puedo vivir así, yo me muero en las minas. ¡Córcholis! Paso las noches llorando, y me muerdo las manos, y... no te asustes, Nela, ni me creas malo por lo que voy a decirte: a ti sola te lo digo (97-98).

Por ello, Casalduero comenta el papel de Celepín en Marianela, diciendo: «en la novela del siglo XIX, tenemos al niño no como en la picaresca, aunque ésta puede ser un precedente histórico, sino como un afán de conocer la infancia y reconocer su sentimiento de rebeldía» (Casalduero, 1993, núm. nota: 6).

En este recorrido sobre la ambición, llegamos al auge representado en la protagonista. Nela, debido a todas las circunstancias que ha sufrido, incluso antes de darse cuenta del sufrimiento, tiene un grado incomparable de anhelo y aspiración para salir de su situación en la cual se vio metida. Al principio, y antes de que Pablo recupere la vista, Nela tiene ambiciones positivas, ya que su felicidad de estar al lado 
de su amado y las promesas de éste la hacen expresar su deseo de tener alas y volar por encima de todo el mundo.

- Aquí estoy, señorito mío. Estaba pensando que por qué no nos daría Dios a nosotras las personas alas para volar como los pájaros. ¡Qué cosa más bonita que hacer zas, y remontarnos y ponernos de un vuelo en aquel pico que está allá entre Ficóbriga y el $\operatorname{mar} ! .$.

- Si Dios no nos ha dado alas; en cambio nos ha dado el pensamiento, que vuela más que todos los pájaros, porque llega hasta el mismo Dios... Dime tú, ¿para qué querría yo alas de pájaro, si Dios me hubiera negado el pensamiento?

- Pues a mí me gustaría tener las dos cosas. Y si tuviera alas, te cogería en mi piquito para llevarte por esos mundos y subirte a lo más alto de las nubes (120).

Pasado el tiempo, frustradas las anhelaciones de Nela y debilitada su voluntad ante las decisiones del destino que cambiaron toda la vida de los protagonistas y encaminaron el provenir de éstos, Nela decide morirse. O sea, cuando se enteró de que Pablo podría recuperar la vista, ver su fealdad física y, por consiguiente, ceder de sus promesas amorosas, no pudo soportar y se retiró.

- ... Efectivamente estás demasiado sola en el mundo... Vamos a ver, Nela, dime ante todo, ¿por qué... pon mucha atención... por qué se te puso en la cabeza quitarte la vida? La Nela no contestó nada.

- Yo te conocí gozosa y al parecer satisfecha de la vida, hace algunos días. ¿Por qué de la noche a la mañana te has vuelto loca?...

- Quería ir con mi madre - repuso la Nela, después de vacilar un instante-. No quería vivir más. Yo no sirvo para nada. ¿De qué sirvo yo? ¿No vale más que me muera? Si Dios no quiere que me muera, me moriré yo misma por mi misma voluntad (207).

En resumen, la ambición forma parte de la lucha con la naturaleza, algo muy necesario para que el ser humano pueda seguir y recoger el resultado de su esfuerzo. Por ello, todos los personajes que disfrutaban de ambiciones y anhelo para superar los tropiezos que obstaculizan su trayectoria lograron su objetivo - los hermanos Golfín-, mientras que los afligidos por la debilidad de la voluntad frustraron, desvanecieron sus sueños y no consiguieron sus propósitos — Nela y Tanasio-. 


\section{Conclusiones}

La creatividad lingüística de Galdós nos ofrece una vez más un quehacer literario que aborda un contundente problema social: la pobreza y el trabajo de los niños en las minas de Socarte, en el norte de España en la segunda mitad del siglo XIX. Paralelamente, se entretejen por los dedos del autor los hilos más finos de una tragedia amorosa en la cual descubrimos otras facetas como el amor y la ambición. Esta última dimensión condujo a algunos personajes al triunfo y la gloria, mientras que llevó a otros a la frustración y la pérdida mortal.

El trasfondo de las historias paralelas de Marianela es sumamente realista, dibujado fidedignamente debido a las andaduras del autor con su amigo Pereda en aquellos espacios y tiempos. La mísera situación del proletariado y el trabajo de los niños en las minas como consecuencia de la pobreza que matiza todo el espacio fueron reflejados con un lenguaje adecuado para los personajes para transmitir su experiencia personal de ver y sentir las dolencias de la sociedad española y la desigualdad social.

Los desbordantes sentimientos de amor y la carga sentimental de Pablo y Nela, asimismo, brotaron de unos corazones semejantes en la realidad, don Benito y Sisita.

Pobreza y amor forman las dos bases de una pirámide escalonada hacia la ambición, la cual controla el comportamiento de los personajes y determina su voluntad. Los hermanos Golfín y el niño Celepín son arquetipos de los personajes ambiciosos, cuyos propósitos estribaban en superar los tropiezos vitales como la pobreza, la miseria y la ignorancia a través de la educación para salvaguardarse.

Nela, cuya voluntad es variable según el estado de ánimo y las circunstancias en que se encuentra, cuando no se planteaba la posibilidad de que Pablo recuperara la vista, tenía una ambición de poseer alas y volar por encima de todo el mundo como referencia a su anhelo de liberarse de las restricciones que la encadenan como su pobreza y fealdad. Esta voluntad se debilita cuando se entera de que Pablo iba a recuperar la vista y ver las cosas como son. Por ello, se retira y le domina un estado de depresión y una voluntad de morirse; y, de hecho, lo alcanza. Su ambición frustrada debido a su pobreza - física y material — y amor no correspondido a Pablo la obsesiona y la mata. 


\section{Bibliografía}

Alonso García, Corina (1989): «Galdós y sus relaciones femeninas: María D. M.», Actas del tercer congreso internacional de estudios galdosianos, Vol. I, Las Palmas de Gran Canaria, Cabildo Insular de Gran Canaria, pp. 11-22.

Aț-Ṭabarī, Abu Ŷa'far (1959): Tārīj Aț-Tabarī: Tārīj al-'umam wal-mulūk, vol 11, Beirut, Dar Suidan.

Behiels, Lieve (2009): «Anagnórisis en Galdós y Dickens», Actas del noveno congreso internacional de estudios galdosianos, Las Palmas de Gran Canaria, Cabildo Insular de Gran Canaria, pp. 440-448.

Boo, Matilde L. (1980): «Galdós y Zola, dos teóricos del teatro», Actas del segundo congreso internacional de estudios Galdosianos II, Vol. II, Las Palmas de Gran Canaria, Cabildo Insular de Gran Canaria, pp. 135-149.

Bravo-Villasante, Carmen (1971): «Aspectos inéditos de Emilia Pardo Bazán (Epistolarios con Galdós)», Actas del séptimo congreso de la asociación internacional de hispanistas, pp. 199-204.

Casalduero, Joaquín (1970): Vida y obra de Galdós, Madrid, Gredos, tercera edición ampliada.

(1993): Prólogo y notas a: Pérez Galdós, Marianela, Madrid, Cátedra.

(1979): «Prólogo» en: Madariaga de la Campa, Pérez Galdós: biografía santanderina, Santander, Institución cultural de Cantabria, $1^{a}$ edición, pp. 1116.

Chaloupková, Kateřina; Eleonora Krupová, Julia; Pešek, Jiří (2016), «Símbolos y sueños en Marianela», en https://is.muni.cz/el/1421/jaro2016/SJIIA110/40759908/_Simbolos_y_sue nos_en_Marianela.pdf (último acceso: 30-10-2018).

Correa, Gustavo (1977): Realidad, ficción y símbolo en las novelas de Pérez Galdós, Madrid, Gredos.

Escolar, Arsenio (2010): «Las mujeres de Galdós», en el 21 febrero de 2010, disponible en: https://blogs.20minutos.es/arsenioescolar/2010/02/21/lasmujeres-galdais/ (último acceso: 28-11-2018).

Esther Jimeno, Juan Calvo; Florencio Magallón; Claudio Segura; Chester Zelaya (1983): Estudios sociales. Nuestro mundo actual: una visión del mundo, América y Costa Rica, Costa Rica, Universidad Estatal a Distancia. 
Fajardo, Trinis Antonietta Messina (2010): «Nombres y símbolos en Marianela de Benito Pérez Galdós», Castilla. Estudios de Literatura, 1, pp. 72-90.

Félix Casanova (2016): «Cartas de amor clandestino entre Galdós y Pardo Bazán formato digital», en Historias de nuestra historia, 2 de noviembre de 2016, disponible en https://hdnh.es/cartas-de-amor-clandestino-entre-galdos-ypardo-bazan-en-formato-digital/ (último acceso: 28-11-2018).

Fernández Montesinos, José (1968): Galdós I, Madrid, Castalia.

Forster, E. M. (2000): Aspectos de la novela, versión española de Guillermo Lorenzo, Barcelona, Debate.

García López, José (1981): Historia de la literatura española, Barcelona, VicensVives.

Gullón, Ricardo (1973): Galdós, novelista moderno, Madrid, Gredos. (1980): Técnicas de Galdós, Madrid, Taurus.

Ḥaqqī, Yaḥya (1992): Kunāsat al-dukkān (Las barreduras de la tienda), al-Qāhira, Dār al-hilāl.

Jones, Charles (1961): «Galdós's Marianela and the Approach to Reality», The Modern Language Review, Vol. 56, (October of 1961), pp. 515-519.

Lambert, A. F. (1973): «Galdós and Concha Ruth Morell», Anales galdosianos, The University of Texas, Austin, año VIII, pp. 33-49.

Ley, Charles David (1977): «Galdós comparado con Balzac y Dickens, como novelista nacional», Actas del primer congreso internacional de estudios Galdosianos, pp. 291-295.

Llano, Manuel (1972): Artículos en la prensa montañesa, tomo II, recopilación e introducción de Ignacio Aguilera, Santander, Institución Cultural de Cantabria.

Madariaga de la Campa, Benito (1979): Pérez Galdós: biografía santanderina, Santander, Institución cultural de Cantabria, $1^{a}$ edición.

Marañón, Gregorio (1962): Amiel: Un estudio sobre la timidez, Madrid, EspasaCalpe.

Pasto-Crosby, Lisa (1990): «Dickens y Galdós: la perspectiva múltiple», Actas del Cuarto Congreso Internacional de Estudios Galdosianos, vol. II, pp. 177188. 
Pattison, Walter T. (1954): Benito Pérez Galdós and the creative process, Minneapolis, University of Minnesota Press.

(1973): «Tow Women in the life of Galdós», Anales galdosianos, The University of Texas, Austin, año VIII, pp. 23-31.

Pérez Galdós, Benito (1999): Ensayos de crítica literaria, edición de Laureano Bonet, Barcelona, Península. (2005): Marianela, edición de Francisco Caudet, Madrid, Cátedra, $5^{\text {a }}$ edición.

Revilla, M. de la (1878): «Revista crítica», en Revista contemporánea, (dirigida por José del Perojo), Año III-IV, Tomo XIV, marzo-abril 1878, Madrid, pp. 505510 .

Sanguino, Julieta (2016), «Incesto y poliamor en la vida de Galdós», CC/Historia, en el 12 de noviembre 2016, disponible en https://culturacolectiva.com/historia/incestos-y-poliamor-en-la-vida-degaldos (último acceso: 29/11/2018).

Sobejano, Gonzalo (1966): «Galdós y el vocabulario de los amantes», en Anales galdosianos, año I, pp. 85-99.

Villanueva, Darío (2011): «Tres teorías, tres realismos: Zola, Galdós, James», 1616: Anuario de Literatura Comparada, (1), pp. 267-291. 